\title{
Abordagem metodológica para o ensino de Arquitetura de Computadores em ambientes não formais
}

\author{
Title: Methodological approach for teaching Computer Architecture in non-formal \\ environments
}

\author{
Carlos Roberto Beleti Junior \\ Universidade Federal do Paraná \\ Campus Jandaia do Sul \\ carlosbeleti@ufpr.br
}

\author{
Robertino Mendes Santiago Junior \\ Universidade Federal do Paraná \\ Campus Jandaia do Sul \\ robertino@ufpr.br
}

\author{
Camila Andrade de Macedo \\ Universidade Federal do Paraná \\ Campus Jandaia do Sul \\ camila.macedo@ufpr.br
}

\author{
Alexandre Prusch Züge \\ Universidade Federal do Paraná \\ Campus Jandaia do Sul \\ alexandrezuge@ufpr.br
}

\author{
Vitor Hugo Santos Alencar \\ Universidade Federal do Paraná \\ Campus Jandaia do Sul \\ vitor.alencar@ufpr.br
}

\begin{abstract}
Resumo
A população brasileira, nos últimos anos, tendo maior contato com máquinas computacionais, precisa compreender o funcionamento dessas máquinas, pois, isso se torna importante para facilitar tarefas do cotidiano como, por exemplo, a aquisição de um computador que atenda às necessidades do indivíduo. Entretanto, para tal, faz-se necessário aprender conceitos da Arquitetura de Computadores, relacionados às características e funcionalidades de hardware de uma máquina computacional, compreendendo as diferenças fundamentais entre componentes físicos e reconhecendo sua utilidade. Tradicionalmente, o ensino de Arquitetura de Computadores é realizado por meio de cursos de graduação ou em cursos técnicos, onde o público-alvo almeja qualificação profissional. Entretanto, raras são as iniciativas de ensino de Arquitetura de Computadores para públicos não iniciados em Computação e sem interesse técnico. O presente trabalho apresenta uma abordagem metodológica para o ensino de Arquitetura de Computadores em ambientes não formais para públicos não iniciados em Computação. Essa abordagem metodológica utiliza-se do Modelo de Rotação por Estações, da Gamificação e da Taxonomia dos Objetivos Educacionais. O público-alvo, deste trabalho, foi de crianças em idade escolar com faixa etária entre 11 a 14 anos. A análise das atividades realizadas demonstrou que a abordagem metodológica foi satisfatória. Os (as) participantes conseguiram atingir os níveis de conhecimento e compreensão do domínio cognitivo e os níveis de recepção, resposta e valorização do domínio afetivo, ambos da Taxonomia dos Objetivos Educacionais. A realização do pré-teste e do pós-teste validam a avaliação realizada pela taxonomia, destacando ganhos em acertos, após a aplicação da abordagem metodológica, de 33 pontos percentuais, em média.
\end{abstract}

Palavras-Chave: Rotação por Estações; Gamificação; Taxonomia dos Objetivos Educacionais; Abordagem Metodológica; Arquitetura de Computadores; Educação não-formal; Ensino de Computação.

\begin{abstract}
The Brazilian population, in recent years, having greater contact with computational machines, needs to understand the functioning of these machines, as knowing how these devices work is important to facilitate everyday tasks, such as choosing the most suitable device considering one's needs. Therefore, it is necessary to learn basic Computer Architecture concepts, regarding the hardware in relation to features and characteristics and considering the differences between physical components, focusing on the utility of each component. Traditionally, computer architecture is taught only in technical and undergraduate courses, where the target audience aims for professional qualification. However, there are few initiatives to teach computer architecture concepts for the general public,
\end{abstract}

Cite as: Beleti Junior, C. R., Macedo, C. A. de, Alencar, V. H. S., Santiago Junior, R. M. \& Züge, A. P. (2020). Methodological approach for teaching Computer Architecture in non-formal environments (Abordagem metodológica para o ensino de Arquitetura de Computadores em ambientes não formais). Brazilian Journal of Computers in Education (Revista Brasileira de Informática na Educação - RBIE), 28, 335-359. DOI: 10.5753/RBIE.2020.28.0.335 
without a pure technical interest. The present work present a methodological approach for teaching computer architecture in non-formal environments, for the general, uninitiated in Computer Science, public. The approach consists in a methodology that applies several teaching and learning tools, such as Station Rotations, Gamification and Taxonomy of Educational Objectives. The target audience of this work were children school, aged between 11 and 14 years old. Based on the analyses of collected data, the methodology was satisfactory. The participants were able to obtain the Knowledge and Comprehension levels from the cognitive domain of Taxonomy of Educational Objectives, and also the receiving, responding and valuing levels from the affective domain. Pretest and posttest results were used to validate the taxonomy evaluation, where correct answers grew by 33 percentage points, in average, after the methodological approach.

Keywords: Station Rotations; Gamification; Taxonomy of Educational Objectives; Methodological Approach; Computer Architecture; non-formal Education; Computer Science Education.

\section{Introdução}

Ao longo das últimas décadas, dispositivos computacionais se tornaram ubíquos e indispensáveis em diversos ambientes da sociedade contemporânea, de modo que conhecimentos sobre Arquitetura de Computadores (AC) são úteis para um público abrangente. O presente texto apresenta um conjunto de procedimentos que será denominado abordagem metodológica e visa o ensino de AC em ambiente não formal, o qual está baseado em metodologias e abordagens de ensino disponíveis na literatura, tais como: a Taxonomia dos Objetivos Educacionais, o Modelo de Rotação por Estações e a Gamificação.

A partir da metade do século XX, os computadores evoluíram e tornaram-se vitais para a sociedade. Recentemente, os smartphones superaram o número de habitantes no Brasil, chegando a 220 milhões de unidades. Quando somados aos computadores, notebooks e tablets, tem-se a impressionante marca de 394 milhões de dispositivos, cerca de 1,9 dispositivo por habitante (Meirelles, 2018).

Tais números sugerem que o contato do brasileiro com máquinas computacionais aumentou significativamente nos últimos anos e, atualmente, as pessoas se relacionam diariamente com tais máquinas, utilizando-as como instrumentos de trabalho, como entretenimento ou para comunicação. Assim, torna-se fundamental ter conhecimento sobre o funcionamento das máquinas computacionais e seus componentes, visto ser útil saber qual a configuração ideal de computador para certas necessidades e o que faz um computador ter melhor desempenho que outro, por exemplo (Macedo et al., 2018).

Em face ao exposto, surgiu, em 2014, o projeto de extensão intitulado Por dentro do computador: uma experiência de popularização da Arquitetura de Computadores, no câmpus avançado em Jandaia do Sul da Universidade Federal do Paraná, onde estão vinculados estudantes e docentes do curso de Licenciatura em Computação. Atualmente o projeto é chancelado pela Sociedade Brasileira de Computação (SBC).

Dessa forma, o presente trabalho apresenta uma abordagem metodológica de ensino de AC em ambiente não formal, além da inserção de um recurso didático usualmente não utilizado na área da Computação, o diorama. O público, para o qual a abordagem metodológica foi aplicada, contou com 160 crianças em idade escolar, com faixa etária entre 11 e 14 anos, de instituições públicas de ensino de Jandaia do Sul (PR). Entretanto, salienta-se que a abordagem metodológica proposta pode ser aplicada a públicos diversos.

Objetiva-se, portanto, apresentar como o público não iniciado pode ter uma visão abrangente dos conceitos da AC, mais precisamente quanto às características e funcionalidades de hardware de uma máquina computacional. Almeja-se mostrar que o público consegue compreender diferenças fundamentais entre componentes físicos e facilmente distinguir funcionalidades atreladas a eles, considerando que, diariamente, podem gerar dúvidas a respeito de suas definições 
e características. Nesse caso, por exemplo, é vital que seja compreendida a diferença entre memória primária e memória secundária.

Este trabalho está organizado da seguinte forma: A Seção 2 apresenta uma visão geral sobre o ensino de AC e formatos em que pode ser ofertado. A Seção 3 descreve as metodologias, métodos e abordagens de ensino que foram consideradas, além de trabalhos relacionados. A Seção 4 descreve a abordagem metodológica desenvolvida e aplicada. Na Seção 5, estão dispostos os resultados alcançados, bem como as dificuldades e limitações encontradas. As considerações finais são apresentadas na Seção 6.

\section{Ensino de Arquitetura de Computadores}

O ensino de AC é, usualmente, abordado por meio de metodologias formais de ensino e de aprendizagem, tal como em cursos técnicos e de graduação, em que o professor apresenta os conceitos teóricos em sala de aula e os estudantes tendem a ser receptores passivos no processo de ensino e de aprendizagem. Além disso, por não haver componente curricular de Informática ou Computação na Educação Básica, crianças em idade escolar não têm acesso a conceitos relacionados à AC, tornando o acesso a esses conhecimentos tardio. Os cursos técnicos, em geral, conhecidos como cursos de montagem e manutenção, se preocupam com características funcionais dos componentes computacionais (hardware), enquanto os cursos de graduação oferecem disciplinas específicas sobre conceitos teóricos em circuitos digitais e organização arquitetural dos componentes de um computador e suas inter-relações. As ofertas de ensino são direcionadas a um público restrito, o qual busca uma formação técnica na área da AC, ocorrendo tradicionalmente em ambientes de educação formal.

A educação formal é caracterizada pela busca e sistematização de conteúdos legitimados pela academia e que normalmente são transmitidos de forma gradativa, ou seja, do simples ao complexo (Feichas, 2007). Para Gohn (2010), a educação formal caracteriza-se como sendo a realizada nas instituições de ensino regulares, como escolas e universidades, nas quais os (as) alunos (as) possuem currículos ou programas especificados por meio de regulamentações, baseadas nas diretrizes nacionais. Ainda, a educação formal "refere-se a tudo o que implica forma, isto é, algo inteligível, estruturado, o modo como algo se configura” (Libâneo, 2008, p.88).

Normalmente, os cursos técnicos fazem uso de metodologias e materiais próprios (apostilas, vídeo-aulas, entre outros) e são norteados por características regionais e de interesse do mercado de trabalho, focados, principalmente, na profissionalização dos (as) participantes, abordando o conhecimento de como realizar manutenção em uma máquina computacional. Em cursos de graduação, a compreensão da estrutura e funcionamento dos componentes físicos, como as unidades que compõem um processador, ou qual a forma de endereçamento entre memória RAM e memória cache, são os tópicos abordados, por exemplo.

Os referenciais de formação para os cursos de graduação em Computação, elaborados pela Sociedade Brasileira de Computação, descrevem que todos os cursos da área da Computação devem compreender o ensino dos conceitos de AC, com maior ou menor profundidade, de acordo com o curso (Zorzo et al., 2017).

Segundo o relatório dos currículos de cursos da Computação, elaborado em conjunto entre a Association for Computing Machinery (ACM), a Association for Information Systems (AIS) e a Computer Society (IEEE-CS) (ACM/AIS/IEEE-CS, 2005), os conceitos a serem abordados para uma disciplina de AC devem ser: organização interna dos componentes integrados dos computadores digitais (processadores, registradores, memória e dispositivos de entrada e saída) e seus conjuntos de instruções. 
Autores, referência em AC, como Stallings (2010), Tanenbaum (2006) e Patterson e Hennessy (2005) também sugerem tópicos disciplinares, sendo divididos em: álgebra booleana e circuitos digitais; estruturas de interconexão do computador; hierarquia dos sistemas de memória; unidade central de processamento; dispositivos de entrada e saída e interfaceamento; avaliação de desempenho e arquiteturas avançadas.

Outro recurso, amplamente empregado no ensino de AC, em ambiente formal, são os simuladores, os quais conseguem ilustrar de forma visual e dinâmica a execução de rotinas e instruções que tratam processos inicialmente abstratos. Inúmeros são os trabalhos que apresentam os mais variados simuladores de movimentação de instruções em arquitetura de processadores, sistemas com simulação de concorrência de processos, simuladores de execução de programas, previsão do comportamento da arquitetura de computadores, entre outros (Borges et al., 2012; Elias et al., 2011; Falcão et al., 2011; Maia et al., 2009; Silva \& Borges, 2016; Ullmann et al., 2014; Verona et al., 2009; Wolff \& Wills, 2000).

Ao utilizar-se de ambientes não formais, surge a educação não formal, a qual não se contrapõe à educação formal, apenas diferem-se quanto às suas características e formas de realização. Para Gohn (2010), a educação não formal ocorre em ambientes construídos em que há intencionalidade da realização do ensino, porém sem a necessária hierarquia de processos institucionalizados de aprendizagem. Gadotti (2005, p.2) descreve que "os programas de educação não formal não precisam necessariamente seguir um sistema sequencial e hierárquico de 'progressão'. Podem ter duração variável, e podem ou não, conceder certificados de aprendizagem”.

Em geral, ações de educação não formal ocorrem em ambientes externos às escolas, sendo propiciadas por meio de projetos em iniciativas de eventos com os mais diversos formatos, tais como: feiras, cursos, museus, entre outros. O público participante dessas ações é heterogêneo e, comumente, não necessita ter conhecimentos prévios sobre os assuntos abordados.

Os museus de ciências são bons exemplos de locais de ocorrência de educação não formal, pois abordam diversas temáticas e não possuem regras formais de normatização de ensino e de aprendizado. Eles se preocupam, simplesmente, com a divulgação científica para um público em geral.

São raras as iniciativas de ensino de AC para públicos não iniciados e sem interesse puramente técnico, sobretudo em ambientes não formais. Público esse interessado somente em conhecer como seu dispositivo computacional (computador, notebook e smartphone, por exemplo) funciona, ou quais os componentes que o compõem, ou, ainda, qual configuração de hardware é mais indicada para sua necessidade.

No Brasil, há apenas projetos de divulgação de Computação, não sendo identificadas outras iniciativas que abordam a educação não formal em AC. O trabalho de Alves et al. (2019) apresenta iniciativas de divulgação e popularização de Computação no cenário nacional em que projetos e programas oferecem ações e atividades lúdicas para públicos não iniciados na área da Computação.

É notório que a AC é uma grande área da Computação composta por diversos tópicos curriculares e com grande importância na sociedade contemporânea. Sobretudo, cabe ressaltar que não é objetivo, deste trabalho, abordá-los em sua totalidade, sequer em profundidade. Vislumbra-se, por meio da abordagem metodológica desenvolvida, apresentar ao público não iniciado na área de Computação uma visão abrangente dos conceitos acerca de AC (hardware de máquinas computacionais) em ambientes não formais. 


\section{Referencial Teórico}

Visando atingir o objetivo proposto, neste trabalho, foi desenvolvida uma abordagem metodológica para o ensino de AC em ambientes não formais, sendo esta abordagem elaborada a partir da combinação de diferentes metodologias, métodos e abordagens conceituadas na literatura, tais como: a Taxonomia dos Objetivos Educacionais, o Modelo de Rotação por Estações e a Gamificação. A forma como tais conceitos são abordados é descrita no decorrer do trabalho.

É importante ressaltar, novamente, o nível de profundidade em que o ensino de AC é aferido pela abordagem metodológica desenvolvida, concentrando-se no conhecimento geral dos componentes físicos de um computador (ou máquinas computacionais), bem como suas características e capacidades. Mantém-se, ainda, um foco sobre as principais diferenças entre conceitos que popularmente causam dúvidas, por exemplo, na diferença entre memória primária (memória RAM) e memória secundária (disco rígido), ou, ainda, porque um smartphone tende a ficar mais lento à medida que grande quantidade de aplicativos vão sendo instalados.

\subsection{Taxonomia dos Objetivos Educacionais}

Na década de 1950, o pedagogo e psicólogo Benjamin Bloom, em parceria com outros pesquisadores e colaboradores da Associação Americana de Psicologia, organizaram uma taxonomia (uma classificação) utilizada para descrever os tipos de aprendizagem e os objetivos educacionais correspondentes, possibilitando o planejamento, a execução e a avaliação de processos educacionais (Filatro \& Bileski, 2015).

Segundo Ferraz e Belhot (2010), a taxonomia é organizada em três possibilidades de aprendizagem, definida pelos domínios Cognitivo, Afetivo e Psicomotor. Cada possibilidade é classificada por uma hierarquia de desenvolvimento, em que o indivíduo atinge o nível subsequente após suprir satisfatoriamente o nível atual. Benjamim Bloom, conforme Filatro e Bileski (2015), dedicou-se a detalhar a taxonomia do domínio cognitivo, a qual ficou popularmente conhecida como Taxonomia de Bloom. Um grupo de pesquisadores ligados a Bloom foi responsável por expor as condutas do domínio afetivo. O domínio psicomotor foi elaborado por outros autores, inspirados pela teoria de Bloom, e não foi adotado neste trabalho, haja vista que o domínio psicomotor está relacionado ao desenvolvimento do aparelho motor, não sendo este o foco do trabalho.

Como a taxonomia apresenta níveis de conhecimento hierárquicos, é possível avaliar os indivíduos a partir do seu "grau" de conhecimento sobre um determinado assunto, tornando-se uma ótima ferramenta de avaliação. Para avaliar o nível de conhecimento atingido por um indivíduo, é necessário, primeiramente, estabelecer em qual dos três domínios de aprendizagem o mesmo está se desenvolvendo, para depois se atentar às palavras chave de cada nível, estabelecidas como verbos por Bloom et al. (1956). Dessa forma é possível perceber que cada nível, dos três domínios, recebe verbos que se distinguem uns dos outros, diferenciando o nível de aprendizado.

Segundo Russell e Airasian (2014), a taxonomia cognitiva é dividida em seis níveis, iniciando do mais simples para o mais complexo; e cada nível subsequente representa um tipo mais complexo de processo cognitivo. A Tabela 1 apresenta a definição acerca de cada nível, bem como os verbos que indicam que determinado nível foi alcançado.

A taxonomia do domínio cognitivo pode ser aplicada em inúmeros contextos, visando sempre o desenvolvimento do indivíduo. Porém, as áreas que mais se apropriam desses estudos derivam de linhas educacionais, isso porque essa taxonomia oferece uma gama de possibilidades e aplicações para aferir o desenvolvimento do aluno, além de oferecer uma base para a elaboração de ferramentas de avaliação (Ferraz \& Belhot, 2010). 
Segundo Wright (2008) e Russell e Airasian (2014), surgiram algumas versões diferentes da taxonomia do domínio cognitivo como, por exemplo, a taxonomia revisada e apresentada pelo grupo liderado por Lorin Anderson (Anderson et al., 2001). Essa taxonomia, assim como a taxonomia original, desenvolvida por Bloom, apresenta seis níveis de habilidades cognitivas, as quais são: lembrar, entender, aplicar, analisar, avaliar e criar. Entretanto, essa taxonomia revisada inclui o nível de profundidade do conhecimento atingido em cada nível das habilidades, sendo factual, conceitual, procedimental e metacognitivo.

Tabela 1: Domínio Cognitivo.

\begin{tabular}{|c|c|c|}
\hline Nível & Definição & Verbos \\
\hline Conhecimento & $\begin{array}{l}\text { Capacidade de lembrar informações ou conteúdos } \\
\text { previamente apresentados. }\end{array}$ & $\begin{array}{l}\text { Identificar, distinguir, reconhecer, } \\
\text { recordar, memorizar e ordenar. }\end{array}$ \\
\hline Compreensão & $\begin{array}{l}\text { Habilidade de entender e compreender conteúdos e } \\
\text { fatos apresentados, podendo a partir disso, explicar e } \\
\text { apresentar o mesmo de outras formas. }\end{array}$ & $\begin{array}{l}\text { Explicar, descrever, definir, converter } \\
\text { e interpretar. }\end{array}$ \\
\hline Aplicação & $\begin{array}{l}\text { Aptidão de utilizar os conhecimentos adquiridos em } \\
\text { outros cenários e contextos. }\end{array}$ & $\begin{array}{l}\text { Aplicar, usar, manipular, modificar, } \\
\text { empregar e ilustrar. }\end{array}$ \\
\hline Análise & $\begin{array}{l}\text { Capacidade de enxergar o conteúdo como um } \\
\text { conjunto de entidades/partes, dividindo-as em } \\
\text { subcategorias e analisando suas inter-relações. }\end{array}$ & $\begin{array}{l}\text { Analisar, reduzir, classificar, separar, } \\
\text { subdividir e examinar. }\end{array}$ \\
\hline Síntese & $\begin{array}{l}\text { Habilidade de organizar o conhecimento adquirido e } \\
\text { criar algo novo. Compreende a capacidade de } \\
\text { combinar as partes para formar um novo todo. }\end{array}$ & $\begin{array}{l}\text { Compilar, combinar, compor, } \\
\text { formular, inventar, desenvolver e } \\
\text { projetar. }\end{array}$ \\
\hline Avaliação & $\begin{array}{l}\text { Habilidade de julgar e estabelecer } \\
\text { posicionamento sobre um determinado assunto. }\end{array}$ & $\begin{array}{l}\text { Avaliar, concluir, validar, julgar e } \\
\text { selecionar. }\end{array}$ \\
\hline
\end{tabular}

Fonte: Adaptado de Ferraz e Belhot (2010).

Apesar da existência das derivações da taxonomia do domínio cognitivo, optou-se, neste trabalho, em um primeiro momento, por avaliar os participantes utilizando a taxonomia original, desenvolvida por Bloom, haja vista que não pertence aos objetivos da abordagem metodológica a determinação da profundidade do conhecimento atingido pelos participantes.

O domínio afetivo envolve categorias ligadas ao desenvolvimento da área emocional e afetiva, englobando sentimentos, atitudes, interesses, preferências, valores e emoções. Como exemplo de características afetivas, pode-se citar a estabilidade emocional, a motivação, a confiabilidade e o autocontrole (Russell \& Airasian, 2014; Ferraz \& Belhot, 2010). Nesse domínio, também, é possível observar os verbos estabelecidos para cada nível, os quais são apresentados na Tabela 2.

Tabela 2: Domínio Afetivo.

\begin{tabular}{|l|l|lr|}
\hline \multicolumn{1}{|c|}{ Nível } & \multicolumn{1}{|c|}{ Definição } & \multicolumn{1}{|c|}{ Verbos } \\
\hline Recepção & $\begin{array}{l}\text { Estar ciente, estar inclinado a prestar atenção. } \\
\text { Permanece passivo em relação a um valor ou } \\
\text { comportamento. }\end{array}$ & $\begin{array}{l}\text { Atender, conscientizar, } \\
\text { reconhecer e receber. }\end{array}$ \\
\hline Resposta & $\begin{array}{l}\text { Exibe alguns comportamentos como resultado da } \\
\text { experiência, aprendendo com a atitude, valor ou } \\
\text { comportamento. Pode não ser permanente. }\end{array}$ & $\begin{array}{l}\text { Comportar-se, obedecer, cooperar e } \\
\text { discutir. }\end{array}$ \\
\hline Valorização & $\begin{array}{l}\text { Demonstra uma atitude positiva em relação a um valor } \\
\text { ou comportamento, mostrando algum envolvimento } \\
\text { ou compromisso. }\end{array}$ & $\begin{array}{l}\text { Aceitar, escolher, difenciar } \\
\text { defender. }\end{array}$ \\
\hline Organização & $\begin{array}{l}\text { Identifica que um novo valor ou um novo } \\
\text { comportamento é importante ou uma prioridade, } \\
\text { podendo estabelecer uma classificação entre as } \\
\text { prioridades. }\end{array}$ & $\begin{array}{l}\text { Adaptar, ajustar, alterar, mudar e } \\
\text { modificar. }\end{array}$ \\
\hline
\end{tabular}


Caracterização por Valores
Atua de forma consistente com o novo valor, sendo o Autenticar, caracterizar, advogar e valor reconhecido como parte do caráter do indivíduo. exibir.

Fonte: Adaptado de Huitt (2001); Kapp et al. (2014).

\subsection{Abordagem de Rotação por Estações}

Conforme Souza e Andrade (2016, p.4), “os processos de ensino e aprendizagem tradicionais não respondem mais às demandas do mundo contemporâneo, muito menos ao perfil do aluno do século XXI”, dessa forma, emerge um modelo de ensino que busca responder a essa demanda. $\mathrm{O}$ Blended Learning, em português, Ensino Híbrido, estabelece-se como uma metodologia de ensino que combina as vantagens da aprendizagem em sala de aula tradicional e a aprendizagem online.

De acordo com Horn e Staker (2015), o Ensino Híbrido consiste em um programa de educação formal em que o aluno ora aprende a partir da interação com seus colegas, em um local físico, com supervisão do professor; ora aprende a partir de instruções e/ou conteúdos online, usufruindo de meios para controlar como, onde e quando vai estudar.

Além disso, essa metodologia dispõe de uma organização de 4 modelos de Ensino Híbrido, sendo eles: Rotation Model, Flex Model, Self-Blended Model e Enriched-Virtual Model, em português, Modelo de Rotação, Modelo Flex, À La Carte e Virtual Enriquecido, respectivamente, conforme ilustra a Figura 1.

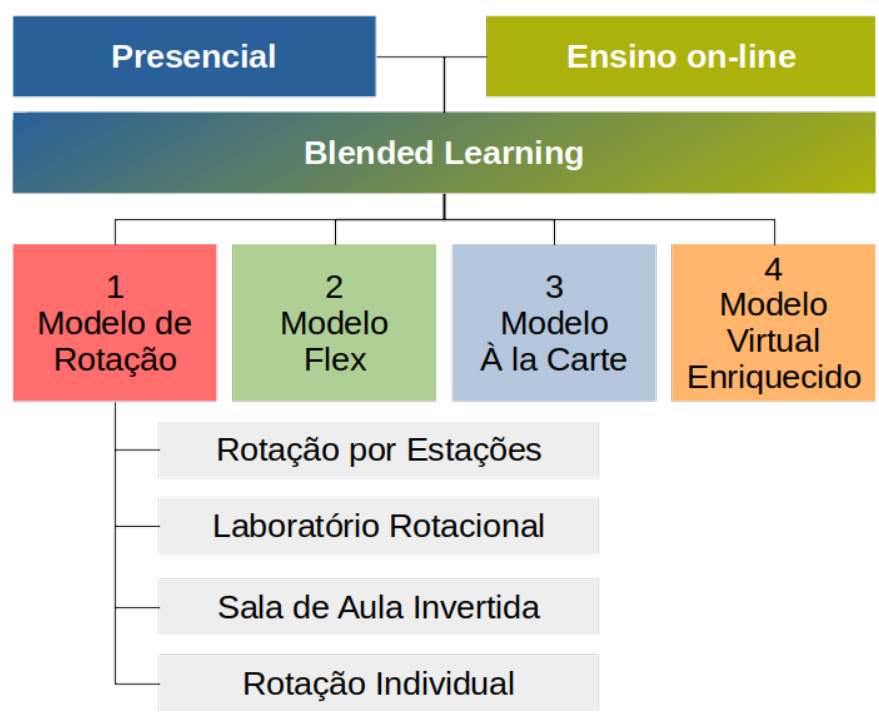

Figura 1: Modelos Blended Learning - Adaptado de Horn e Staker (2015).

Segundo Horn e Staker (2015), o Modelo de Rotação permite que os (as) alunos (as) rotacionem - seguindo uma programação fixa ou a critério do professor - pelas estações de aprendizagem, onde, pelo menos em uma delas, realiza alguma atividade online. Conforme ilustrado na Figura 1, esse modelo possui ramificação: Modelo de Rotação por Estações, Laboratório Rotacional, Sala de Aula Invertida e Rotação Individual.

Em diversas situações, o Modelo de Rotação por Estações é implantado dentro da sala de aula tradicional com o objetivo de motivar os (as) alunos (as) e adaptar o modelo de ensino, empregado nas Escolas/Universidades, conforme a tecnologia avança. O trabalho de Alessandro et al. (2018) utiliza o Modelo de Rotação por Estações na disciplina de Ciências, cursada por alunos (as) do $4^{\circ}$ ano do Ensino Fundamental. No presente trabalho, conceitos do Modelo de Rotação por Estações servem de base na composição desta abordagem metodológica, conforme apresentado na Seção 4. 


\subsection{Gamificação}

A gamificação pode ser entendida como um conjunto de estratégias que busca envolver o público em um determinado contexto, visando uma maior participação do mesmo. Essa proposta é bastante aceita e, por isso, é utilizada em diversos cenários. Derivada do mundo dos jogos, a gamificação busca trazer dinâmicas para engajar as pessoas (Lopes, Toda, \& Brancher, 2015).

Na educação, a gamificação vem sendo a vitrine para os pesquisadores na busca por estratégias que envolvam os (as) alunos (as) no processo de aprendizagem. Por envolver um pacote muito amplo de estratégias, a gamificação acaba por ser uma ferramenta objetiva para cada contexto, adquirindo forma ímpar em cada situação. Conforme Challco et al. (2016), para utilizar a gamificação, deve-se tomar cuidado com o planejamento das atividades, pois um mau desenho das mesmas pode gerar resultados indesejados, pois seus efeitos dependem muito do contexto onde essa tecnologia é aplicada.

Os elementos extraídos do mundo dos jogos digitais podem ser divididos em dois grupos, definidos por elementos intrínsecos e extrínsecos. Segundo Zichermann e Cunningham (2011), os elementos intrínsecos são característicos de cada usuário ou inerentes ao comportamento humano não estando, necessariamente, descritos ou destacados. Como exemplo de elemento intrínseco, tem-se a competição, a qual é percebida como um importante estímulo no ambiente do jogo. Na ocasião, os usuários são estimulados a uma rivalidade, despertando um desejo de querer ser melhor que os demais jogadores. Visto que tal estímulo é despertado de maneira individual, a competição é entendida como um forte elemento intrínseco.

Os elementos extrínsecos, por sua vez, estão evidenciados como recompensas e gratificações, os quais são enaltecidos por fatores externos como o meio em que o jogador é inserido. Um exemplo de elemento extrínseco é a narrativa pela qual, a partir de um enredo pré-definido, o jogador é envolvido por um conjunto de informações pertinentes ao mundo do jogo. Ela é responsável por nortear os jogadores, além de se adaptar (em alguns casos) ao comportamento dos mesmos. Segundo Zichermann e Cunningham (2011), a ausência desse elemento pode causar uma desorientação ou abandono do jogador por falta de objetividade.

Lopes et al. (2015), também, realizaram um estudo preliminar sobre esses elementos e averiguaram seus impactos motivacionais nos usuários por meio de respostas obtidas na aplicação de questionários. Foi observado que informações em forma de narrativas e níveis, durante os jogos, são relevantes, segundo os jogadores respondentes. Esses ainda recomendaram utilização de conquistas e placares para estímulo durante as competições.

Com o exposto, almeja-se, neste trabalho, utilizar os conceitos e elementos da gamificação como forma de aumentar o engajamento do público participante da abordagem metodológica apresentada na Seção 4.

\subsection{Trabalhos relacionados}

Conforme destacado, a investigação por trabalhos de ensino de AC, em ambientes não formais, para públicos não iniciados em Computação, em bases de dados científicos, periódicos e anais de eventos científicos da área, não retornou resultados quanto a pesquisas de mesma natureza e com características equivalentes. Trabalhos relevantes foram encontrados pela decomposição do gênero do presente trabalho em três categorias, a saber: ensino de AC; ensino de Computação para públicos não iniciados; métodos e metodologias de ensino na Computação.

\subsubsection{Ensino de Arquitetura de Computadores}

São várias as propostas de ensino de AC (também apresentado como Organização e Arquitetura de Computadores), geralmente, em disciplinas curriculares em cursos de graduação e cursos técnicos, cujo objetivo é a compreensão do funcionamento lógico de cada elemento dentro de uma 
arquitetura computacional. Tais disciplinas são amparadas por autores conceituados como Patterson e Hennessy (2005), Tanenbaum (2006) e Stallings (2010) e, além dos livros didáticos, ferramentas e sistemas têm sido utilizados como amparo ao ensino em disciplinas de AC, tais como os simuladores. Estes têm o objetivo de facilitar o entendimento dos (as) alunos (as), pois, a arquitetura de um sistema computacional tende a ser um conhecimento abstrato e complexo de se compreender.

Kurniawan e Ichsan (2017) analisaram diversos simuladores como apoio no processo de ensino para cursos de graduação da área da Computação. No estudo, são propostos simuladores para diferentes conteúdos disciplinares dentro da AC, tais como: o funcionamento do computador ENIAC, ciclo de busca e execução de processos, funcionamento de processadores por meio de instruções em linguagens de baixo nível, projeto e implementação de circuitos lógicos, gerenciamento de processos e memória na camada do sistema operacional. Outros trabalhos encontrados, também, realizaram análises comparativas entre simuladores (Radivojevic et al., 2018; Esmeraldo et al., 2019).

Tem-se, portanto, o uso de simuladores, no ensino de AC para estudantes de cursos de graduação, na área da Computação. Nesse sentido, trabalhos empregam metodologias que se utilizam de aulas teóricas, livros didáticos, vídeos e simuladores (Otero \& Aravind, 2018; Mendes et al., 2018), utilizando, ainda, simuladores junto a sistemas com placas físicas de treinamento (Topaloglu et al., 2018), além de abordagens com uso de gamificação (Costa et al., 2018) e realidade aumentada (da Silva et al., 2018). Pesquisas, ainda, demonstram programação e simulação de processadores, nas disciplinas de Arquitetura e Organização de Computadores (Brox et al., 2018; Radivojevic et al., 2018) e, também, em disciplinas relacionadas a Compiladores (Vieira et al., 2015), atestando, em sua maioria, a eficácia do seu uso como ferramenta de apoio ao ensino. Alguns trabalhos, os quais utilizam simuladores para o ensino de AC, propõem o aferimento dos resultados, relacionados à satisfação dos (as) alunos (as), por meio de questionários (Otero \& Aravind, 2018; Radivojevic et al., 2018; Esmeraldo \& Lisboa, 2017), comparativos de desempenho dos (as) alunos (as), nas disciplinas (Vieira et al., 2015), ou análises, considerando ambos os aspectos (Fernandes \& Silva, 2017).

\subsubsection{Ensino de Computação para públicos não iniciados}

De modo geral, a Computação é abordada em temas transversais a outras áreas, quando direcionada a crianças em idade escolar, justamente como prevê a Base Nacional Comum Curricular (BNCC), cujos conhecimentos e habilidades relativos à Computação e a tecnologias são divididos em três temáticas principais: pensamento computacional, mundo digital e cultura digital (BRASIL, 2017). O currículo de Referência em Tecnologia e Computação, por exemplo, é um material desenvolvido para auxiliar a inserção de temáticas de Computação e de tecnologia, nas áreas previstas pela BNCC. No currículo, encontram-se diversas atividades, práticas pedagógicas e sugestões de materiais de referência para apoiar o ensino de conceitos computacionais e de tecnologia que contemplam as habilidades requeridas aos (às) alunos (as) em cada nível escolar (Raabe et al., 2018).

Outro referencial de tais atividades, voltadas a essa mesma categoria, é a obra intitulada “Computação e o Mundo: livro do professor” que apresenta atividades sobre Computação para estudantes do $9^{\circ}$ ano, do Ensino Fundamental (Araujo et al., 2020). O livro apresenta uma atividade inteiramente voltada para, conforme descrito pelos autores, "arquitetura de hardware dos computadores”, fazendo menção ao conhecimento dos componentes físicos de uma máquina computacional. Uma referência que também trabalha conceitos computacionais e teve repercussão, pois, aborda o ensino de conceitos computacionais sem o uso de computadores, foi o trabalho de Bell et al. (2011), destacando-se que apresenta, quase que em sua totalidade, 
atividades que compreendem áreas de lógica e algoritmos, não se atentando a atividades de hardware, por exemplo.

\subsubsection{Métodos e metodologias de ensino na Computação}

Nessa categoria, pesquisas aparecem divididas entre as principais metodologias utilizadas neste: Modelo de Rotação por Estações, Gamificação e Taxonomia dos Objetivos Educacionais.

Nos trabalhos que apresentam a utilização da metodologia de Rotação por Estações, para o ensino de conceitos de Computação, em geral, constata-se que a rotação, por apresentar um formato lúdico e diferente de metodologias tradicionais, faz com que o aluno tenha maior curiosidade e participe mais ativamente (Kohler et al., 2019; Barion \& Melli, 2019). Junto à Rotação por Estações, outras metodologias podem ser incorporadas como o método Peer Instruction, formando a chamada abordagem híbrida. Oliveira (2019) descreve a integração experimental em uma disciplina de programação, comparando estratégias híbridas à tradicional, apresentando melhores resultados de desempenho naquelas. Nesse horizonte, pesquisas internacionais têm abordado estratégias híbridas de rotação, como a rotação individual combinada com grupos de discussão, trabalhos práticos de laboratório e projetos (Yang \& Newman, 2019), rotação por laboratórios no ensino do Pensamento Computacional (Cai et al., 2018), ambos demonstrando que tais abordagens têm sido bem sucedidas em seus estudos.

O ensino de programação, em cursos de Computação, pode apresentar um diferencial quando a gamificação é aplicada, associada a técnicas de engajamento com a Taxonomia de Bloom (Silva et al., 2018). Nessa mesma direção, trabalhos têm argumentado que a gamificação pode criar um ambiente propício ao aprendizado de programação, aumentando o interesse dos (as) alunos (as) pela área, desde que tenha um planejamento adequado, conforme os objetivos educacionais (Papadakis \& Kalogiannakis, 2017). Estudos empíricos, comparando elementos da gamificação, tem atestado o aumento na eficácia e motivação dos (as) alunos (as), no aprendizado de programação (Khaleel et al., 2019; Marín et al., 2018; Ribeiro, 2018). Outro aspecto considerado, na utilização de gamificação, tem sido os ambientes e plataformas de programação online que visam aumentar o interesse, a participação e o empenho dos estudantes (Silva et al., 2018; Ribeiro, 2018), além de frameworks desenvolvidos com estratégias de gamificação para orientar educadores na aprendizagem de programação, em ambientes online (Piteira et al., 2018; Khaleel et al., 2017).

Quanto à Taxonomia dos Objetivos Educacionais, aplicada ao ensino de Computação, uma revisão sistemática da literatura é encontrada em Masapanta-Carrión e Velázquez-Iturbide (2018), em que aponta que a taxonomia é utilizada, principalmente, no ensino de programação e na avaliação do desempenho dos (as) alunos (as) e, além disso, apresenta algumas dificuldades em sua implementação quanto à classificação dos objetivos educacionais e especificação do conhecimento associado aos domínios. Em trabalhos que consideram o ensino do Pensamento Computacional (Sarawagi, 2014; Selby, 2015; López \& García-Peñalvo, 2016) e na utilização da aprendizagem baseada em problemas (Rodrigues \& dos Santos, 2013; dos Santos, 2016), a taxonomia, também, encontra-se com boa representação, especialmente, na definição dos processos educacionais e na avaliação de desempenho.

\section{Abordagem Metodológica}

A abordagem metodológica proposta, no presente trabalho, apresenta um ambiente não formal de aprendizagem por meio do ensino de conteúdos relacionados a AC. Baseada no Modelo de Rotação por Estações, a abordagem metodológica proposta é composta por cinco estações de aprendizagem, sendo elas: 1) O levantamento do conhecimento prévio e conhecimento adquirido; 2) O processo de inicialização de um computador real; 3) A apresentação dos principais 
componentes de um computador e seu funcionamento; 4) Um passeio por dentro de um computador e; 5) Uma gincana de atividades, conforme ilustra a Figura 2. Ao finalizarem as atividades, na estação 5 , os participantes são direcionados novamente à estação 1 , para que seja possível mensurar o conhecimento adquirido. O tempo total para a realização das atividades propostas, em todas as estações, é de 50 minutos, sendo destinados 5 minutos para o levantamento do conhecimento prévio, 5 minutos para o levantamento do conhecimento adquirido e 10 minutos para as demais estações.

Antes dos participantes (público-alvo) percorrerem as cinco estações, os mesmos são divididos em duas equipes e identificados com crachás com seus nomes e com a respectiva equipe (equipe A ou B), favorecendo as identificações antes da $5^{\mathrm{a}}$ estação, na gincana promovida entre as equipes. Durante toda a aplicação da abordagem metodológica, as equipes competem entre si, sendo os pontos contabilizados por meio de perguntas realizadas pelo público, acerca dos conceitos apresentados em cada uma das estações, ou seja, quem participa fazendo perguntas relevantes soma pontos para sua equipe.

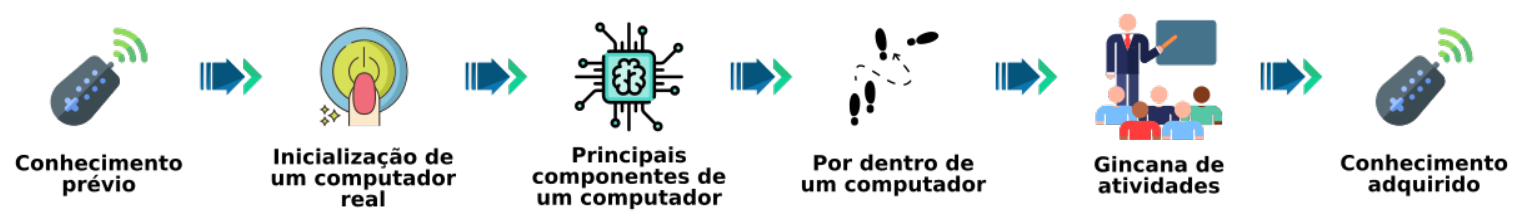

Figura 2: Estações que compõem a abordagem metodológica.

Ademais, o comportamento de cada participante, bem como de suas ações, também, são registrados durante as atividades previstas, com o objetivo de constituir informações suficientes para que as análises mediadas pela Taxonomia dos Objetivos Educacionais possam ser validadas. Ao final, os pontos obtidos por cada equipe, durante as cinco estações, são somados e a equipe vencedora recebe brindes. O objetivo e as atividades de cada estação são descritos nas próximas subseções.

\subsection{Estação “Conhecimento Prévio e Conhecimento Adquirido”}

A primeira estação consiste no levantamento do conhecimento de cada participante, antes e depois da aplicação da abordagem metodológica, na qual o público é convidado a responder algumas questões básicas relacionadas à AC. São perguntas de múltipla escolha com cinco alternativas, sendo uma delas verdadeira e as demais falsas. A Tabela 3 representa tais questões.

Tabela 3: Questões referentes ao conhecimento prévio dos alunos.

\begin{tabular}{|l|}
\hline \multicolumn{1}{|c|}{ Questões } \\
\hline 1) O que é hardware? \\
\hline 2) Qual dispositivo fornece energia para os componentes do computador? \\
\hline 3) Unidade Central de Processamento é o mesmo que: \\
\hline 4) Qual componente perde os dados quando o computador é desligado? \\
\hline 5) Qual o dispositivo é responsável por gerenciar o processamento gráfico do computador? \\
\hline 6) São dispositivos de entrada e saída: \\
\hline 7) Os barramentos da placa-mãe são responsáveis pela conexão dos componentes do computador. Pode-se \\
afirmar que:
\end{tabular}

As respostas são coletadas, utilizando um sistema de resposta à audiência (clicker) (Araújo et al., 2011), e armazenadas no software para posterior conferência. Ressalta-se que as respostas são coletadas de forma anônima. A Figura 3 ilustra os clickers utilizados. Importante destacar que, no levantamento prévio do conhecimento, a resposta correta de cada pergunta não é exibida para os participantes. Cada participante tem acesso à resposta correta após responder ao questionário que mensura o conhecimento adquirido. 

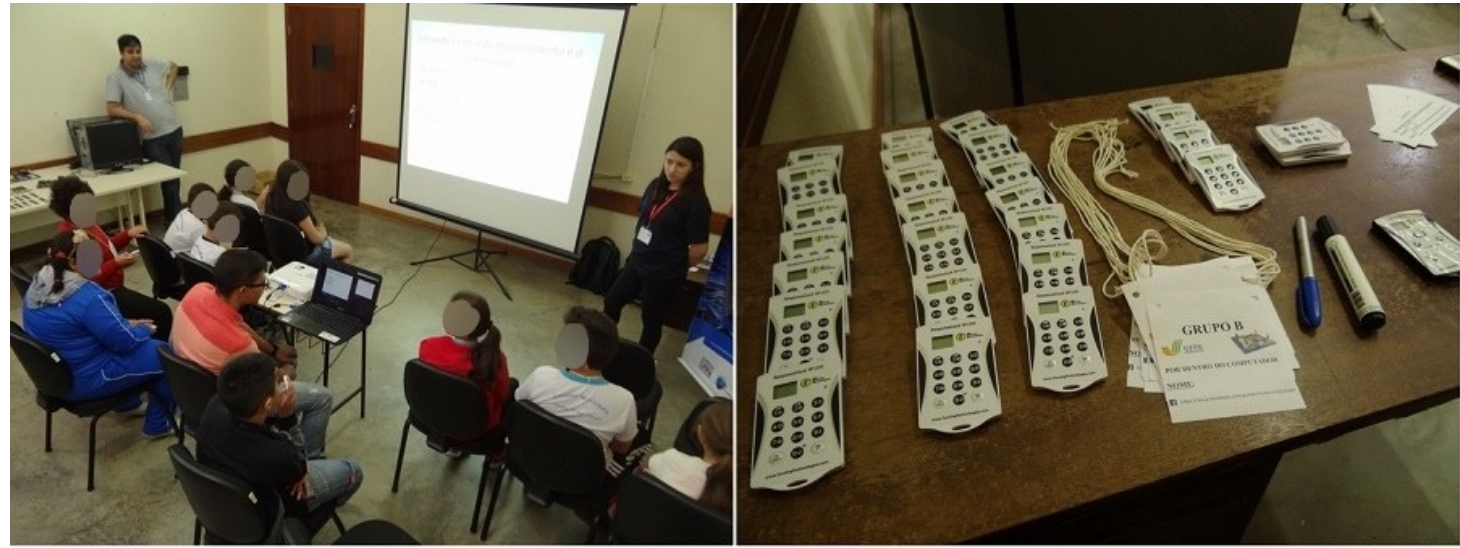

Figura 3: Primeira estação - Conhecimento prévio e conhecimento adquirido.

As informações registradas são de extrema importância tanto para mensurar o conhecimento prévio dos participantes, quanto para verificação da corretude das respostas de cada equipe. Conforme observado, anteriormente, as respostas corretas correspondem a pontos contabilizados para a respectiva equipe. A pontuação de cada atividade será apresentada na Seção 4.5.

\subsection{Estação “Inicialização de um computador real”}

A segunda estação, ilustrada pela Figura 4, consiste na inicialização de um computador real, cujo objetivo é explicar o funcionamento geral de um computador, a partir do momento em que a energia é liberada até a inicialização do sistema operacional e o carregamento de programas na memória primária.

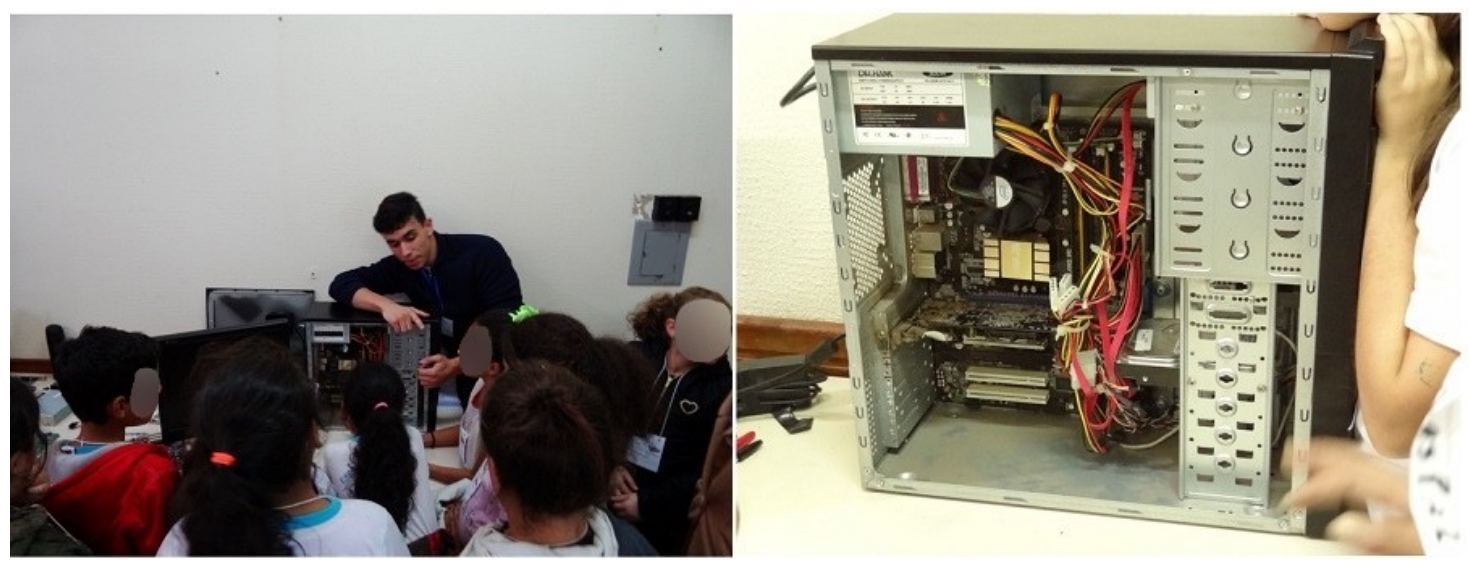

Figura 4: Segunda estação - Inicialização de um computador real.

Nessa estação, são apresentados os componentes que compõem uma máquina computacional, bem como a importância de cada um. Realizam-se, nessa estação, ações como: retirada da memória RAM de seu slots e tentativa de ligar o computador; retirada do cabo de distribuição de energia da fonte de energia e tentativa de ligar o computador; retirada do cabo de distribuição de energia do disco rígido e tentativa de ligar o computador; entre outras ações que, de algum modo, tornam o computador inapto a ser utilizado. Tais ações são realizadas com o objetivo de explicar aos participantes, por meio de exemplos reais, a importância de cada componente da unidade computacional.

\subsection{Estação "Principais componentes de um computador"}

Na terceira estação, são expostos ao público diferentes componentes internos de um computador real, com o objetivo de apresentar as características e funcionalidade de cada um, separadamente, e, por fim, a forma como os componentes comunicam-se entre si, conforme ilustra a Figura 5. 


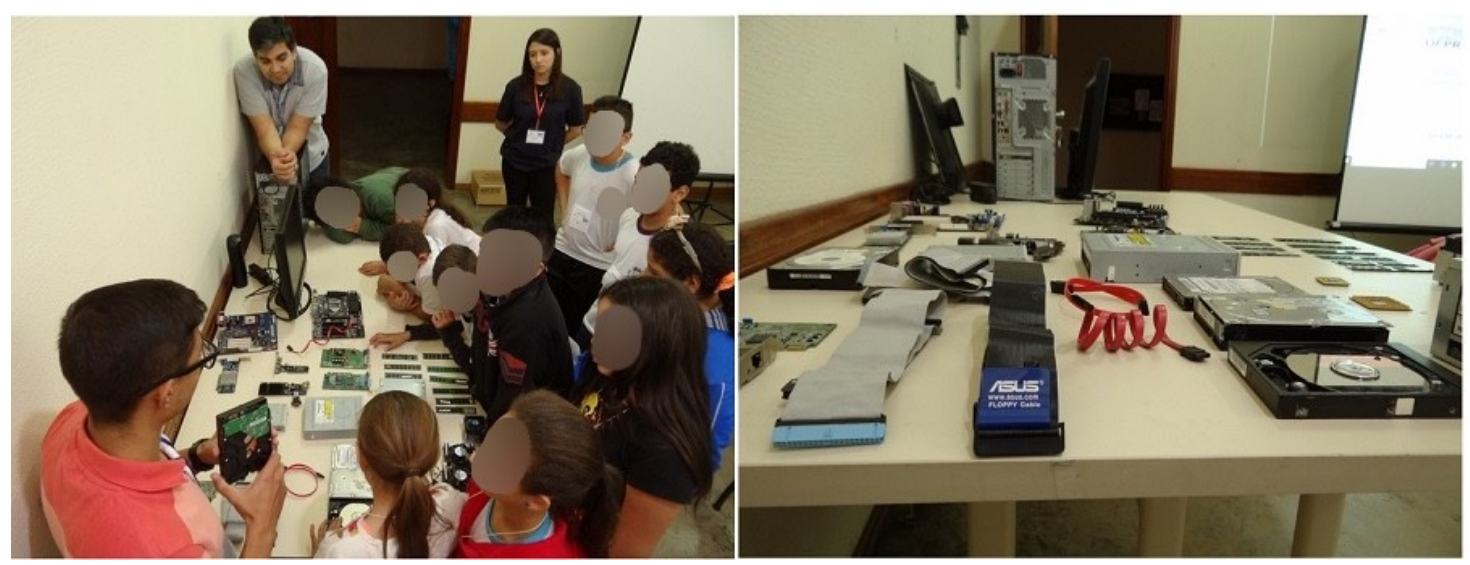

Figura 5: Terceira Estação - Principais componentes de um computador.

Nessa estação, diversos componentes são apresentados, desde itens, hoje, obsoletos para uso em computadores pessoais, como o drive de disquete 3,5 polegadas, até componentes mais atuais como processadores de última geração.

Como os componentes estão sem a alimentação de energia, o público pode manusear, encaixar e desencaixar componentes em seus slots. É comum, na estação, o surgimento de dúvidas referentes a novas e antigas tecnologias disponíveis no mercado. Ainda, nessa, é apresentado um apanhado geral do histórico dos computadores, descrevendo como foi a evolução dos componentes no decorrer dos anos e dos avanços quanto às novas tecnologias.

\subsection{Estação "Por dentro de um computador"}

A quarta estação expõe os conceitos de uma maneira instigante, atrativa e inovadora, utilizandose do diorama como material didático-pedagógico. Tal diorama consiste em um cenário construído de modo a simular ambientes reais (Ash, 2004), tipicamente originário das Ciências Naturais (Marandino \& Laurini, 2018; Beleti Junior et al., 2015), neste caso, foi construído para simular os principais componentes internos de um computador. Os componentes do diorama foram construídos, em escala aumentada em quinze vezes, e dispostos em uma sala com dimensão de quatro metros de largura por cinco metros de comprimento, ilustrando um "computador gigante”. O objetivo de utilizar tais representações é proporcionar ao público uma experiência contemporânea e transformadora, onde são convidados a "caminhar por dentro de um computador” (Alves et al., 2019). Conforme ilustra a Figura 6, a representação dos principais componentes está exposta para o público, permitindo aos participantes caminharem entre os componentes. O objetivo, dessa estação, é despertar o interesse do público a respeito dos conceitos já apresentados, além de incentivar a curiosidade e estimular perguntas. 


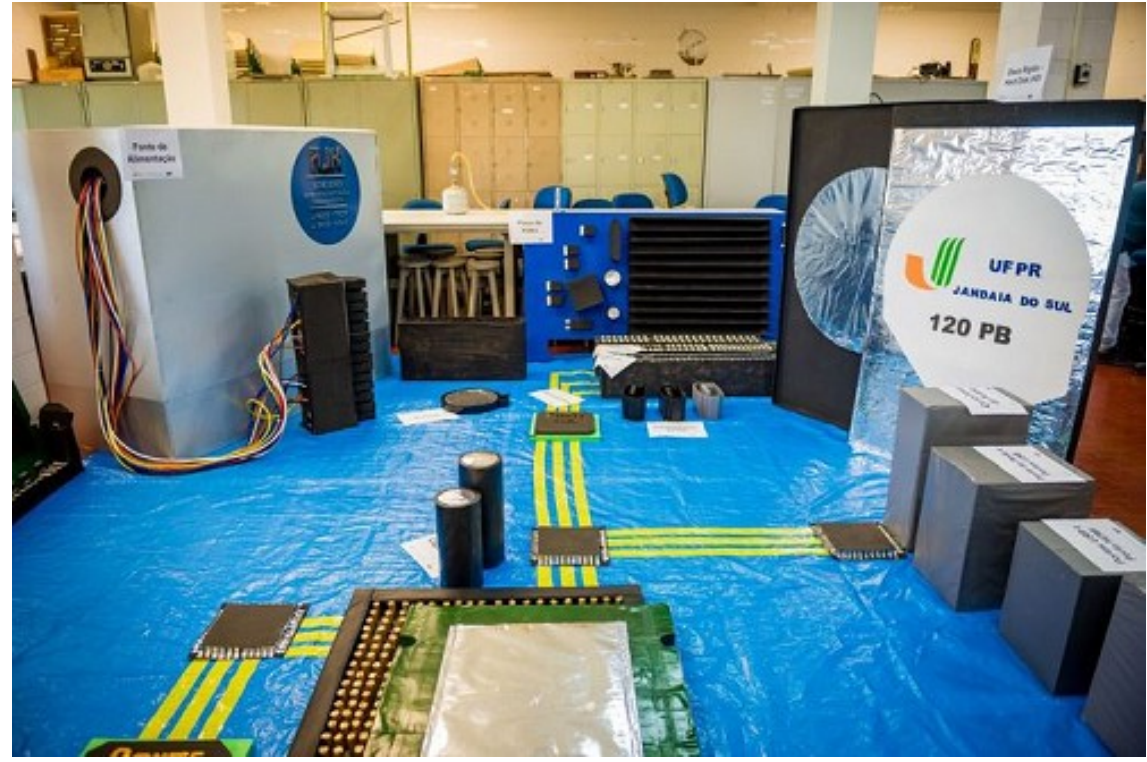

Figura 6: Quarta Estação - Por dentro de um computador.

Conforme observado, anteriormente, o diorama mostrou-se o recurso educacional de maior destaque, estimulando sensações de espanto e deslumbre por parte do público participante. Nessa estação, cada componente do diorama recebe um número de identificação, o qual será utilizado na estação da gincana, conforme descrito na próxima subseção. Os componentes identificados, no diorama, são: Memória RAM, Disco Rígido, Processador, Fonte de Alimentação, Placa de Vídeo, entrada USB, Barramentos, Bateria e Conectores de Áudio e Vídeo, Ponte Norte e Ponte Sul.

\subsection{Estação “Gincana de atividades"}

A quinta e última estação consiste em uma gincana, onde as equipes são submetidas a diversas perguntas acerca dos conceitos apresentados durante toda a aplicação da abordagem metodológica. A pontuação da gincana é determinada conforme Tabela 4.

Tabela 4: Atividades e pontuações.

\begin{tabular}{|l|c|}
\hline \multicolumn{1}{|c|}{ Atividade } & Pontuação \\
\hline 1) Realizar pergunta coerente & 1.5 pontos \\
\hline 2) Responder pergunta corretamente & 2 pontos \\
\hline 3) Realizar analogia coerente & 2 pontos \\
\hline 4) Citar exemplo coerente & 1.5 pontos \\
\hline 5) Identificar componente do diorama & 1.5 pontos \\
\hline
\end{tabular}

A cada atividade efetuada de forma correta, a pontuação é atribuída à equipe que acertou. As atividades enumeradas de 1 a 4 (Tabela 4) são realizadas pelas equipes no decorrer das estações e contabilizadas por meio da anotação dos condutores das atividades, os quais observam a abordagem metodológica e a participação do público, com objetivo de pré-identificar os níveis atingidos, estabelecidos por meio da Taxonomia dos Objetivos Educacionais, utilizada neste trabalho, conforme Seção 3.1.

Na atividade 5, da gincana, são distribuídas, para cada equipe, questões sobre a funcionalidade de um determinado componente, conforme ilustrado na Tabela 5. Nessa atividade, a cada uma das questões, as equipes devem atribuir o nome do componente ao respectivo número de identificação, conforme indicado na tabela. O número identificador foi atribuído a cada componente em suas respectivas representações no diorama, podendo ser visualizados na quarta estação. Ao final, da estação 5, somam-se os pontos atribuídos a cada equipe e a equipe vencedora é premiada. 


\section{Resultados e discussão}

Conforme descrito, anteriormente, a proposta da abordagem metodológica é atingir públicos-alvo não iniciados e sem interesse técnico em Computação, com o objetivo de divulgar o conhecimento computacional sobre Arquitetura de Computadores, especificamente, sobre hardware de máquinas computacionais.

Durante toda a aplicação da abordagem metodológica, a gamificação foi empregada por meio da atribuição de pontos e concessão de premiações. Dessa forma, o público foi estimulado a participar das atividades, possibilitando a mensuração dos níveis atingidos nos domínios cognitivo e afetivo, estabelecidos pela Taxonomia dos Objetivos Educacionais.

Tabela 5: Questões utilizadas durante a gincana - funcionalidades dos principais componentes de um computa
\begin{tabular}{|l|}
\hline Questões \\
\hline 1) Qual componente armazena os dados temporariamente? \\
\hline 2) Qual componente perde os dados quando o computador é desligado? \\
\hline 3) Qual componente salva os dados permanentemente? \\
\hline 4) Qual componente realiza o processamento das informações? \\
\hline 5) Que componente é conhecido como CPU? \\
\hline 6) Que componente é conhecido como Disco Rígido? \\
\hline 7) Quem fornece energia para todos os componentes do computador? \\
\hline 8) Qual componente é responsável por gerenciar o processamento gráfico do computador? \\
\hline 9) Quem serve de conector para mouse, teclado e pen drive? \\
\hline 10) Quem realiza a comunicação entre os componentes internos do computador? \\
\hline 11) Quem é responsável por manter data e hora atualizados no computador? \\
\hline 12) Quem serve de conector para áudio e vídeo? \\
\hline
\end{tabular}

A aplicação da abordagem metodológica contou com a participação de 160 alunos e alunas, com faixa etária entre 11 a 14 anos, matriculados (as) em escolas e colégios públicos, de Jandaia do Sul/PR, entre os meses de agosto e setembro de 2018, divididos em 10 turmas, com, aproximadamente 16 alunos (as).

Os resultados foram observados em cada uma das cinco estações descritas, na Seção 4. Na estação 1, a qual tinha o objetivo de realizar um levantamento sobre o conhecimento prévio de cada participante, verificou-se que os participantes obtiveram taxas de acertos relativamente baixas, sendo as perguntas 4, 1 e 7, as que possuíram as menores taxas com, 10,56\%, 12,42\% e 18,01\%, respectivamente. Esses dados são apresentados e analisados mais adiante, na Tabela 7. Todas as perguntas realizadas no levantamento prévio sobre o conhecimento dos (as) alunos (as) podem ser visualizadas na Tabela 3, da Seção 4.1.

As estações 2 e 3, as quais abordaram o processo de inicialização de um computador real e a apresentação dos principais componentes de um computador, bem como seu funcionamento, respectivamente, serviram para a apresentação desses componentes. Nessas estações, o comportamento dos participantes (reações, afirmações e questionamentos) foi observado, sendo registrada a participação destes, a fim de ajudar na identificação do nível atingido na Taxonomia dos Objetivos Educacionais. Cabe ressaltar que as informações sobre os diversos componentes de uma máquina computacional, a integração entre eles e seus funcionamentos foram apresentadas ao público da abordagem metodológica.

A estação 4, onde os participantes "passearam por dentro do computador”, visitando os componentes em escala aumentada (diorama), o comportamento dos participantes também foi observado e os dados foram registrados, uma vez que estes identificaram, no diorama, os seus respectivos componentes de uma máquina computacional. 
Na última etapa da abordagem metodológica, como descrito, anteriormente, todos os (as) alunos (as) foram convidados (as) para participarem de uma gincana de perguntas e respostas. Os (as) alunos (as) participaram de maneira direta, respondendo às questões de forma competitiva. $\mathrm{O}$ teor competitivo foi instigado pela gamificação que, por outro lado, impulsionou o público, de maneira saudável, a participar da atividade proposta.

Após a realização da abordagem metodológica, foi possível aferir, por meio da Taxonomia dos Objetivos Educacionais, que os participantes conseguiram atingir os níveis de conhecimento e de compreensão do domínio cognitivo e os níveis de recepção, resposta e valorização do domínio afetivo. A Tabela 6 sintetiza os níveis alcançados.

Tabela 6: Níveis Atingidos pela Taxonomia dos Objetivos Educacionais.

\begin{tabular}{|c|c|}
\hline Domínio & Nível Atingido \\
\hline \multirow[t]{2}{*}{ Domínio Cognitivo } & $\begin{array}{l}\text { Conhecimento: Os (as) alunos (as) conseguiram atingir o nível de } \\
\text { conhecimento porque conseguiram identificar os componentes do } \\
\text { computador representados por diorama, em escala aumentada. } \\
\text { Verbos relacionados: Identificar, distinguir, memorizar e reconhecer. }\end{array}$ \\
\hline & $\begin{array}{l}\text { Compreensão: Com a participação, na gincana, os (as) alunos (as) } \\
\text { conseguiram responder às perguntas, explicando e definindo as funções } \\
\text { dos componentes com suas próprias palavras, atingindo assim o nível de } \\
\text { compreensão. } \\
\text { Verbos relacionados: Explicar, descrever e definir. }\end{array}$ \\
\hline \multirow[t]{3}{*}{ Domínio Afetivo } & $\begin{array}{l}\text { Recepção: Foi possível verificar que os (as) alunos (as) prestaram } \\
\text { atenção às explicações e conscientizaram-se sobre a importância das } \\
\text { máquinas computacionais. } \\
\text { Verbos relacionados: Conscientizar, observar, reconhecer e receber. }\end{array}$ \\
\hline & $\begin{array}{l}\text { Resposta: Houve alunos (as) que complementaram falas de outros } \\
\text { alunos (as), a fim de responder corretamente o solicitado. } \\
\text { Verbos relacionados: Obedecer, cooperar e discutir. }\end{array}$ \\
\hline & $\begin{array}{l}\text { Valorização: Os (as) alunos (as) foram submetidos a um jogo de } \\
\text { perguntas e respostas referentes aos temas explicados durante as } \\
\text { atividades. Com essa atividade foi possível verificar que os (as) alunos } \\
\text { (as) responderam prontamente às perguntas solicitadas. } \\
\text { Verbos relacionados: Aceitar, diferenciar e defender. }\end{array}$ \\
\hline
\end{tabular}

Conforme observado, na Tabela 6, os participantes, ao conseguirem IDENTIFICAR os componentes do computador, no diorama, conseguiram RECONHECER esses componentes em escala aumentada, atingindo o nível de conhecimento do domínio cognitivo. Da mesma forma, quando os (as) alunos (as) conseguiram EXPLICAR a função dos componentes, com as próprias palavras, DEFININDO-AS, estes (as) alcançaram o nível de compreensão do domínio cognitivo.

Em relação ao domínio afetivo, identificou-se que os (as) alunos (as) atingiram o nível de recepção ao OBSERVAR, atentamente, as explicações dadas sobre cada componente e RECONHECERAM a importância que as máquinas computacionais têm na sociedade e a importância de cada componente para o funcionamento do computador. O nível de resposta foi alcançado pelo fato dos (as) alunos (as) COOPERAREM uns com os outros, complementando as respostas dos (as) colegas, DISCUTINDO sobre o conteúdo, a fim de responderem corretamente. Durante o jogo de perguntas e respostas, foi observado que os (as) alunos (as) conseguiram DIFERENCIAR os conceitos associados entre os componentes e DEFENDERAM as respostas como sendo as corretas, desta forma, foi aferido que estes (as) atingiram o nível de valorização.

Após a gincana, foi realizado o pós-teste, o qual sustenta os resultados obtidos pela Taxonomia dos Objetivos Educacionais, nos domínios cognitivo e afetivo, sendo possível constatar que as perguntas realizadas e respondidas, no início da aplicação da abordagem 
metodológica, tiveram uma melhora significativa nas taxas de acertos, sendo, assim, compreendidas e, por consequência, corretamente respondidas (observadas).

A Tabela 7 apresenta as taxas de acerto das perguntas durante o pré-teste e o pós-teste. Para todas as questões, os resultados obtidos, no pós-teste, foram superiores aos obtidos durante o préteste. A média de acertos, no pré-teste, foi de 26,44\%, com desvio padrão de 13,08\%; enquanto, a média, no pós-teste, foi de 59,72\%, com desvio padrão de 15,96\%. Pela aplicação de uma análise de variância (ANOVA), foi possível observar que a média de acertos, no pré-teste, foi, estatisticamente, diferente da média de acertos no pós-teste, com $p<0,05$.

Tabela 7: Taxas de acertos no pré-teste e no pós-teste.

\begin{tabular}{|c|c|c|}
\hline Questão & Acertos no pré-teste & Acertos no pós-teste \\
\hline 1 & $12,42 \%$ & $43,48 \%$ \\
\hline 2 & $26,09 \%$ & $72,05 \%$ \\
\hline 3 & $38,51 \%$ & $43,48 \%$ \\
\hline 4 & $10,56 \%$ & $73,29 \%$ \\
\hline 5 & $37,89 \%$ & $82,61 \%$ \\
\hline 6 & $41,61 \%$ & $49,69 \%$ \\
\hline 7 & $18,01 \%$ & $53,42 \%$ \\
\hline
\end{tabular}

Identificar e descrever as causas dos diferentes resultados obtidos, por meio das respostas às questões, não foi uma tarefa usual. Ao examinar as anotações, a equipe responsável pela condução das atividades, evidenciou que o componente memória RAM, abordado na questão 4, foi objeto de destaque nas falas e motivo de curiosidade dos participantes, o que pode ser um indicativo da melhora nos percentuais no pós-teste, dessa questão. Quanto à análise dos resultados menos significativos (questões 3 e 6, respectivamente) e quanto ao comparativo no pré e pós-testes, ressalta-se que, em ambas as questões, os participantes tiveram dificuldades em distinguir a resposta correta das demais, o que gerou um quantitativo de respostas imprecisas tanto no préteste, quanto no pós-teste.

Para realizar essa análise, a aplicação da abordagem metodológica foi conduzida por quatro pessoas, três estudantes e um docente. Dentre esses, dois estudantes ficaram responsáveis, especificamente, para analisar o comportamento dos (as) alunos (as) e anotar qualquer tipo de reação dos mesmos. Além dessas anotações, houve atividades em que os (as) alunos (as) respondiam por escrito o nome e a função de cada componente do diorama, os quais foram enumerados, individualmente. A Figura 7 destaca em vermelho tais numerações.

Dessa forma, foi possível analisar, com maior rigor, a participação dos (as) alunos (as) e os domínios atingidos pelos (as) mesmos (as). Para isso, o registro das respostas deles foi fundamental na análise sobre o comportamento destes (as) durante toda a aplicação da abordagem metodológica. Como já observado, anteriormente, foram registradas todas as ações e percepções por parte dos (as) alunos (as) participantes em cada estação, o que colaborou para que níveis de domínios dentro da Taxonomia dos Objetivos Educacionais fossem alcançados. 


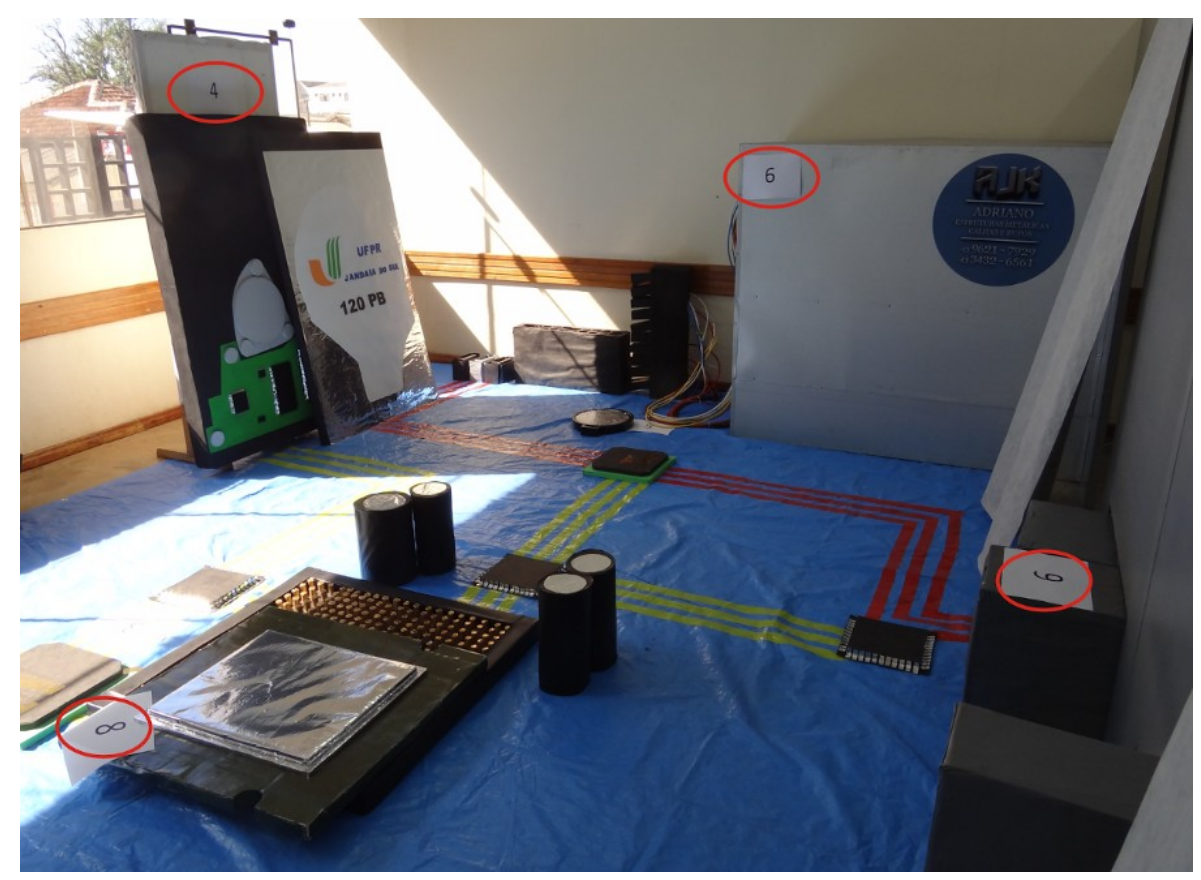

Figura 7: Componentes do diorama enumerados.

\section{Considerações Finais}

Compreender como as máquinas computacionais funcionam, bem como a importância dos principais componentes dessas máquinas, tornou-se necessário para uma grande parcela da população, haja vista que esse conhecimento facilita a realização de tarefas do cotidiano, como, por exemplo, a compra de um computador, tablet ou um smartphone, que atenda às necessidades de cada consumidor.

Este trabalho visou apresentar uma abordagem metodológica de ensino de AC, desenvolvida a partir da integração de metodologias e abordagens de ensino, para públicos não iniciados em Computação, em ambientes não formais. A abordagem metodológica utilizou-se do Modelo de Rotação por Estações, Gamificação e Taxonomia dos Objetivos Educacionais.

O Modelo de Rotação por Estações serviu de base para organizar a abordagem metodológica como um ambiente de aprendizagem, sendo constituído por cinco estações, a saber: estação do conhecimento prévio, estação de inicialização de um computador real, estação dos principais componentes de um computador, estação por dentro do computador e estação de gincana de atividade. Cabe ressaltar que a estação de conhecimento prévio foi utilizada para a aplicação do pré-teste e pós-teste, visando mensurar o nível de aprendizagem dos participantes e validar a efetividade da abordagem metodológica.

Com a utilização da gamificação, durante a aplicação da abordagem metodológica, foi possível observar que os (as) alunos (as) foram motivados a serem mais ativos (as), pois, o estímulo, pela recompensa, incentivou coletivamente os (as) mesmos (as) a participarem das atividades propostas. Esse fator gerou não somente o interesse dos (as) alunos (as) em participar, como, também, propiciou um ambiente favorável para o desenvolvimento do trabalho em equipe.

Utilizou-se a Taxonomia dos Objetivos Educacionais como uma ferramenta de avaliação durante as atividades. Para tal, os domínios cognitivo e afetivo apresentaram os níveis mais adequados para a metodologia utilizada, neste trabalho, sendo atingidos os níveis de conhecimento e compreensão (cognitivo) e recepção, resposta e valorização (afetivo). Porém, novas etapas da abordagem metodológica (que devem ser incorporadas futuramente) poderão, potencialmente, 
usufruir do domínio psicomotor da taxonomia. Pretende-se, por exemplo, incorporar à abordagem metodológica uma estação em que os alunos confeccionem alguns tipos de materiais (como a elaboração de bonecos didáticos ou réplicas de componentes do computador em menor escala). Nesse caso, os alunos estariam em um processo de desenvolvimento desse domínio.

Na aplicação do pré-teste, em que o conhecimento prévio dos participantes é aferido, notouse que a pergunta 4 foi a que possuiu a menor média de acertos, sendo atingido apenas 10,56\%, e a pergunta que obteve a maior taxa de acertos, com 41,61\%, foi a pergunta 6 . Após a aplicação da abordagem metodológica, os (as) participantes foram submetidos ao pós-teste, onde se observou um aumento significativo nas médias de acertos para todas as perguntas, sendo as perguntas $1 \mathrm{e}$ 3 , aquelas com as menores médias (empatadas com 43,48\%), e, com a maior média de acertos, foi a pergunta 5 (82,61\%). Destaca-se, nesta análise, a pergunta 4, como a de maior ganho em acertos, após a aplicação da abordagem metodológica, com uma melhoria de 62,73 pontos percentuais. Destaca-se ainda que o pré-teste e o pós-teste não foram realizados com a pretensão de inferir níveis de aprendizado mas teve a intenção de esclarecer quais foram os conceitos apresentados, durante a atividade, que evidenciaram maior compreensão por parte dos (as) participantes, além de indicar pontos que devem ser melhor apresentados. Porém, é evidente que melhorias nos percentuais, em todas as questões do pós-teste, podem ser, ao menos, indicativos de conhecimentos propiciados ou de boas experiências vivenciadas.

A análise da abordagem metodológica apresenta resultados interessantes, considerando-se o formato da atividade e o período de tempo em que foi realizada, cerca de 50 minutos, visto que o aprendizado de conceitos técnicos e não usuais, no cotidiano, pelo público-alvo não se mostra favorável nesse curto espaço temporal. Outro fator a ser observado é quanto ao ambiente, pois, trata-se de um espaço não formal, diferente daquele da sala de aula tradicional, onde o aluno é o receptor dos conteúdos apresentados pelo professor. Ao contrário, tem-se um grande envolvimento do público com as estações de aprendizado e com os condutores das atividades, o que favorece o aprendizado.

Com o exposto, tem-se a ciência de que não existem métodos de ensino ou metodologias comprovadamente eficientes para o ensino de AC (hardware) para um público não iniciado, mas, apresentou-se, neste trabalho, uma abordagem metodológica desenvolvida e aplicada com resultados alvissareiros. Almeja-se, portanto, com tal abordagem e com os resultados apresentados, neste trabalho, contribuir com trabalhos e iniciativas de ensino, nessa área de conhecimento, além de divulgar e popularizar a Informática na Educação, bem como o curso de Licenciatura em Computação.

\section{Agradecimentos}

O presente trabalho foi realizado com apoio institucional da Universidade Federal do Paraná, por meio da Pró-Reitoria de Extensão e Cultura (PROEC) e Programa Licenciar da Pró-Reitoria de Graduação e Educação Profissional (PROGRAD).

\section{Referências}

ACM/AIS/IEEE-CS (2005). Computing curricula 2005 - the overview report. the joint taskforce on computing curricula IEEE-CS/ACM (Tech. Rep.). Los Alamitos: Author.

Alessandro, A. S. R. D., Dias, K. C. B., Vilela, D. C., \& Germano, J. S. E. (2018). Aprendizado híbrido no ensino de ciências - experiência de uso das TIC com rotação por estações em uma turma de $4^{\circ}$ ano do ensino fundamental. CIET:EnPED. [GS Search] 
Alves, G. J., Gonçalves, D. C. M., Züge, A. P., Beleti Junior, C. R., \& Santiago Junior, R. M. (2019). Por dentro do computador: uma iniciativa de divulgação e popularização da arquitetura de computadores. In E. S. Lisbôa \& V. Rosa (Eds.), As tecnologias digitais e o ensino de ciências e de computação na sociedade contemporânea (p. 162-172). Palotina: Booknando Livros.

Anderson, L. E., Krathwohl, D. E., Airasian, P., Cruikshank, K., Mayer, R., Pintrich, P., . . . Wittrock, M. (2001). A taxonomy for learning, teaching, and assessing: a revision of Bloom's taxonomy of educational objectives. New York: Longman.

Araujo, L., Santana, B., \& Bittencourt, R. (2020). Computação e o mundo: Livro do professor. Feira de Santana: [s.n.].

Araújo, G. H. M., Silva, A. S. C., Carvalho, L. A. S., Silva, J. C., Rodrigues, C. W. M. S., \& Oliveira, G. F. (2011). O quiz como recurso didático no processo ensino-aprendizagem em genética. In Anais da 63a reunião anual da SBPC. Goiânia.

Ash, D. (2004). How families use questions at dioramas: Ideas for exhibit design. Curator: The Museum Journal, 47(1), 84-100. DOI: 10.1111/j.2151-6952.2004.tb00367.x [GS Search]

Barion, E., \& Melli, N. (2019, 04). Os modelos de rotação por estação e laboratório rotacional no ensino híbrido do curso técnico de informática semipresencial: um novo olhar dentro e fora da sala de aula. In Grandes Temas da Educação Nacional (4th ed., p. 123-131). Belo Horizonte: Atena Editora. DOI: 10.22533/at.ed.34019020412 [GS Search]

Beleti Junior, C. R., Valerio, M., Santiago Junior, R. M., Züge, A. P., Silva, E. S. A., Albuquerque, J. B. C., . . . Geremias, J. E. S. (2015). Caminhando por dentro do computador: uma experiência de educação e popularização da ciência e tecnologia. In Anais do $33^{\circ}$ seminário de extensão universitária da região sul. Bagé: Unipampa.

Bell, T., Witten, I. H., Fellows, M., Adams, R., \& McKenzie, J. (2011). Ensinando ciência da computação sem o uso do computador. Computer Science Unplugged ORG. [GS Search]

Bloom, B. E., Engelhart, M., Furst, E., Hill, W., \& Krathwohl, D. (1956). Taxonomy of educational objectives, handbook I: The cognitive domain. New York: David McKay Co Inc.

Borges, E. V. C. L., Andrezza, I. L. P., Falcão, E. l., Silva, G. S., \& Silva, H. S. (2012, 01). Seac: Um simulador online para ensino de arquitetura de computadores. In Anais do wscad-weac 2012 - workshop sobre educação em arquitetura de computadores (p. 34-38). DOI: 10.13140/2.1.3581.3764 [GS Search]

BRASIL (2017). Base Nacional Comum Curricular. Brasília: MEC. Disponível em: http://basenacionalcomum.mec.gov.br/images/BNCC_20dez_site.pdf.

Brox, M., Gersnoviez, A., Montijano, M. A., Herruzo, E., \& Moreno, C. D. (2018, June). SICOME 2.0: A teaching simulator for computer architecture. In 2018 XIII technologies applied to electronics teaching conference (taee) (p. 1-7). DOI: 10.1109/TAEE.2018.8476041 [GS Search]

Cai, J., Yang, H. H., Gong, D., MacLeod, J., \& Jin, Y. (2018). A case study to promote computational thinking: The lab rotation approach. In S. K. Cheung, L.-f. Kwok, K. Kubota, L.-K. Lee, \& J. Tokito (Eds.), Blended learning. enhancing learning success (pp. 393- 403). Cham: Springer International Publishing. DOI: 10.1007/978-3-319-94505-7_32 [GS Search]

Challco, G., Mizoguchi, R., \& Isotani, S. (2016). An ontology framework to apply gamification in cscl scenarios as persuasive technology. Revista Brasileira de Informática na Educação, 24(02), 67. DOI: 10.5753/rbie.2016.24.02.67 [GS Search]

Costa, R., Bernardo, A., \& Lucena, I. (2018). Incentivando a aprendizagem de arquitetura de 
computadores em cursos de computação através de um simulador do microprocessador z- 80 com kahoot! Anais do Workshop de Informática na Escola, 24(1), 710. DOI: 10.5753/cbie.wie.2018.710 [GS Search]

da Silva, G., Oliveira, L. C., \& Fernandes, S. R. (2018). Uso de realidade aumentada para ensino de arquitetura de computadores com MIPS. In Anais do XXVI workshop sobre educação em computação. Porto Alegre, RS, Brasil: SBC. DOI: 10.5753/wei.2018.3531 [GS Search]

dos Santos, S. C. (2016). PBL-SEE: An authentic assessment model for PBL-Based software engineering education. IEEE Transactions on Education, 60(2), 120-126. DOI: 10.1109/TE.2016.2604227 [GS Search]

Elias, W. J., Silva, J. R. C., \& Tiola, F. P. S. (2011, 07). Simulador multiciclo do processador MIPS 32 bits para apoio ao estudo em arquitetura de computadores. RENOTE - Revista Novas Tecnologias na Educação, 9(1). DOI: 10.22456/1679-1916.21988 [GS Search]

Esmeraldo, G., \& Lisboa, E. B. (2017). Uma ferramenta para exploração do ensino de organização e arquitetura de computadores. International Journal of Computer Architecture Education, 6, 68-75. [GS Search]

Esmeraldo, G., Mendes, C. S., Fontes, L., \& Lisboa, E. (2019). Um estudo comparativo entre simuladores computacionais para apoio à disciplina de arquitetura e organização de computadores. In Anais do IV congresso sobre tecnologias na educação (pp. 434-443). Porto Alegre, RS, Brasil: SBC. DOI: 10.5753/ctrle.2019.8915 [GS Search]

Falcão, E., Borges, E., Andrezza, I., Silva, G., Wanderley, K., Cavalcante, B., \& Silva, H. (2011, 01). Ambiente de simulação gráfica 3D para ensino da arquitetura de processadores. In $X I X$ workshop sobre educação em computação (wei) (p. 1639-1646). DOI: $\underline{10.13140 / 2.1 .1877 .4406}$ [GS Search]

Feichas, H. (2007). Processos de aprendizagem formal e informal na universidade brasileira. XVI Encontro Anual da ABEM e Congresso Regional da ISME América Latina, 1-8.

Fernandes, S. R., \& Silva, I. S. (2017). Relato de experiência interdisciplinar usando MIPS. International Journal of Computer Architecture Education (IJCAE), 6(1), 52-61. [GS $\underline{\text { Search }] ~}$

Ferraz, A. P. d. C. M., \& Belhot, R. V. (2010, 00). Taxonomia de Bloom: revisão teórica e apresentação das adequações do instrumento para definição de objetivos instrucionais. Gest. Prod., 17, 421 - 431. DOI: 10.1590/S0104-530X2010000200015 [GS Search]

Filatro, A. C., \& Bileski, S. (2015). Produção de conteúdos educacionais. São Paulo: Saraiva. [GS Search]

Gadotti, M. (2005). A questão da educação formal/não-formal. Sion: Institut Internacional des Droits de $1^{\circ}$ Enfant, 1-11. [GS Search]

Gohn, M. G. (2010). Educação não formal e o educador social: atuação no desenvolvimento de projetos sociais. São Paulo: Cortez.

Horn, M., \& Staker, H. (2015). Blended: Usando a inovação disruptiva para aprimorar a educação. Porto Alegre: Penso Editora. [GS Search]

Huitt, W. (2001). Taxonomy of the affective domain. Educational Psychology Interactive. Disponível em: http://www.edpsycinteractive.org/topics/affect/affdom.html

Kapp, K. M., Blair, L., \& Mesch, R. (2014). The gamification of learning and instruction fieldbook: Ideas into practice. San Francisco: Wiley. [GS Search]

Khaleel, F. L., Ashaari, N. S., \& Wook, T. S. M. T. (2019, 02). An empirical study on gamification 
for learning programming language website. Jurnal Teknologi, 81, 151-162. DOI: 10.11113/jt.v81.11133 [GS Search]

Khaleel, F. L., Ashaari, N. S., Wook, T. S. M. T., \& Ismail, A. (2017). Methodology for developing gamification-based learning programming language framework. In 2017 6th international conference on electrical engineering and informatics (iceei) (p. 1-6). DOI: 10.1109/ICEEI.2017.8312378 [GS Search]

Kohler, L., Mattos, M., Silveira, H., Fronza, L., Santos, B., Largurá, L., . . W Wuo, A. (2019, 11). Uso da metodologia de rotação por estações com a computação desplugada. In (p. 427). DOI: $\underline{10.5753 / \text { cbie.wcbie.2019.427 [GS Search] }}$

Kurniawan, W., \& Ichsan, M. H. H. (2017, Sep.). Teaching and learning support for computer architecture and organization courses design on computer engineering and computer science for undergraduate: A review. In 4th international conference on electrical engineering, computer science and informatics (EECSI) (p. 1-6). DOI: 10.1109/EECSI.2017.8239076 [GS Search]

Libâneo, J. C. (2008). Pedagogia e pedagogos para quê? (10th ed.). São Paulo: Editora Cortez.

Lopes, R., Toda, A., \& Brancher, J. (2015). Um estudo preliminar sobre conceitos extrínsecos e intrínsecos do processo de gamification. Revista Brasileira de Informática na Educação, 23(03), 164-173. DOI: 10.5753/rbie.2015.23.03.164 [GS Search]

López, A. R., \& García-Peñalvo, F. J. (2016). Relationship of knowledge to learn in programming methodology and evaluation of computational thinking. In Proceedings of the fourth international conference on technological ecosystems for enhancing multiculturality (pp. 7377). New York: Association for Computing Machinery. DOI: $\underline{10.1145 / 3012430.3012499}$ [GS Search]

Macedo, C. A., Alencar, V. H. S., Züge, A. P., Beleti Junior, C. R., \& Santiago Junior, R. M. (2018). Abordagem didático-pedagógica para o ensino de arquitetura de computadores em espaços educacionais não formais. In Anais do IX computer on the beach (pp. 890-892). Florianópolis: Universidade do Vale do Itajaí.

Maia, D. W. N., Vieira, M. M., \& Pessoa, R. F. (2009, 01). PS-CAS MIPS: Um simulador de pipeline do processador MIPS 32 bits para estudo de arquitetura de computadores. In Workshop sobre educação em arquitetura de computadores (WEAC) (p. 56-59). [GS Search]

Marandino, M., \& Laurini, C. (2018). A compreensão da biodiversidade por meio dioramas de museus de zoologia: um estudo com público adulto no Brasil e na Dinamarca. Ensaio Pesquisa em Educação em Ciências (Belo Horizonte), 20. DOI: 10.1590/1983211720182001018 [GS Search]

Marín, B., Frez, J., Cruz-Lemus, J., \& Genero, M. (2018, November). An empirical investigation on the benefits of gamification in programming courses. ACM Transactions on Computing Education, 19(1). DOI: 10.1145/3231709 [GS Search]

Masapanta-Carrión, S., \& Velázquez-Iturbide, J. A. (2018). A systematic review of the use of Bloom's taxonomy in computer science education. In Proceedings of the 49th acm technical symposium on computer science education (pp. 441-446). New York: Association for Computing Machinery. DOI: 10.1145/3159450.3159491 [GS Search]

Meirelles, F. S. (2018). Pesquisa anual do uso de TI nas empresas (Tech. Rep. No. 29). São Paulo: FGVcia, FGV-EAESP.

Mendes, C. S., Fontes, L., Lisboa, E., \& Esmeraldo, G. (2018). Uma abordagem integrada de hardware e software para o ensino de organização e arquitetura de computadores. Brazilian 
Symposium on Computers in Education (Simpósio Brasileiro de Informática na Educação SBIE), 29(1), 1711. DOI: 10.5753/cbie.sbie.2018.1711 [GS Search]

Oliveira, M. A. F. (2019). Estratégia híbrida para o processo ensino-aprendizagem baseada na participação ativa e avaliações integradas. (teste de doutorado), Universidade Federal do Rio Grande do Sul, Porto Alegre. [GS Search]

Otero, R. R., \& Aravind, A. (2018). Teaching computer architecture labs using a MCU platform. In Proceedings of the 23rd western canadian conference on computing education (pp.3:13:6). New York, NY, USA: ACM. DOI: 10.1145/3209635.3209651 [GS Search]

Papadakis, S., \& Kalogiannakis, M. (2017). Using gamification for supporting an introductory programming course. the case of classcraft in a secondary education classroom. In A. L. Brooks, E. Brooks, \& N. Vidakis (Eds.), Interactivity, game creation, design, learning, and innovation (pp. 366-375). Cham: Springer International Publishing. DOI: 10.1007/978-3319-76908-0_35 [GS Search]

Patterson, D. A., \& Hennessy, J. L. (2005). Organização e projeto de computadores - a interface hardware/software (third ed.). São Paulo: Campus Elsevier.

Piteira, M., Costa, C., \& Aparicio, M. (2018, 04). Computer programming learning: How to apply gamification on online courses? Journal of Information Systems Engineering \& Management, 3(2). DOI: $\underline{10.20897 / j i s e m .201811}$ [GS Search]

Raabe, A. L. A., Brackmann, C. P., \& Campos, F. R. (2018). Currículo de referência em tecnologia e computação: da educação infantil ao ensino fundamental. Centro de Inovação para a Educação Básica-CIEB.

Radivojevic, Z., Stanisavljevic, Z., \& Punt, M. (2018). Configurable simulator for computer architecture and organization. Computer Applications in Engineering Education, 26(5), 1711-1724. DOI: 10.1002/cae.22034 [GS Search]

Ribeiro, R. B. S. (2018). Utilizando gamificação em um sistema de juiz online para engajar alunos de graduação em disciplinas iniciais de programação. (dissertação de mestrado). [GS Search]

Rodrigues, A., \& dos Santos, S. (2013). Aplicando a taxonomia de Bloom revisada para gerenciar processos de ensino em sistemas de aprendizagem baseada em problemas. Revista Brasileira de Informática na Educação, 21(01). DOI: 10.5753/rbie.2013.21.01.01 [GS Search]

Russell, M., \& Airasian, P. (2014). Avaliação em sala de aula: Conceitos e aplicações (7th ed.). Rio de Janeiro: AMGH Editora. [GS Search]

Sarawagi, N. (2014, jun). A flipped CS0 classroom: Applying blooms taxonomy to algorithmic thinking. Journal of Computing Sciences in Colleges, 29(6), 21-28. [GS Search]

Selby, C. (2015). Relationships: computational thinking, pedagogy of programming, andbloom's taxonomy. In The 10th workshop in primary and secondary computing education (pp. 8087). [GS Search]

Silva, G., \& Borges, J. A. (2016, 10). Simus: Um simulador para o ensino de arquitetura de computadores. In International journal of computer architecture education (ijcae) (Vol. 5, p. 7-12).

Silva, T., Melo, J., \& Tedesco, P.(2018). Um modelo para promover o engajamento estudantil no aprendizado de programação utilizando gamification. Revista Brasileira de Informática na Educação, 26(03), 120. DOI: 10.5753/rbie.2018.26.03.120 [GS Search] 
Souza, P. R., \& Andrade, M. D. C. F. (2016). Modelos de rotação do ensino híbrido: estações de trabalho e sala de aula invertida. Revista E-Tech: Tecnologias para Competitividade Industrial, 9(1), 03-16. [GS Search]

Stallings, W. (2010). Arquitetura e organização de computadores (8th ed.). São Paulo: Prentice Hall.

Tanenbaum, A. S. (2006). Organização estruturada de computadores (5th ed.). São Paulo: Prentice Hall.

Topaloglu, N., Sahin, S., \& Uluyol, Ç. (2018, 01). Comparing the effectiveness of a microprocessor training system and a simulator to teach computer architecture. International Journal of Engineering Education, 34(3), 1138-1144. [GS Search]

Ullmann, M. R. D., Inocêncio, A. C. G., Moraes Neto, E. D., Freitas, M. S., \& Parreira Júnior, P. A. (2014). Neandersim: Simulador gráfico de apoio ao ensino de arquitetura de computadores. In XXII workshop sobre educação em computação (p. 1647-1656).

Verona, A. B., Martini, J. A., \& Gonçalves, T. L. (2009). SIMAEAC: Um simulador acadêmico para ensino de arquitetura de computadores. Varia Scientia, 9(16), 139-148. [GS Search]

Vieira, P., Zeferino, C., \& Raabe, A. (2015). Avaliação empírica da proposta interdisciplinar de uso dos processadores BIP. Revista Brasileira de Informática na Educação, 23(02), 99-110. DOI: $\underline{10.5753 / \text { rbie.2015.23.02.99 [GS Search] }}$

Wolff, M., \& Wills, L. (2000). SATSim: A superscalar architecture trace simulator using interactive animation. In Proceedings of the 2000 workshop on computer architecture education. New York, NY, USA: ACM. DOI: 10.1145/1275240.1275249 [GS Search]

Wright, R. (2008). Educational assessment: Tests and measurements in the age of accountability. SAGE Publications.

Yang, S., \& Newman, R. (2019). Rotational blended learning in computer system engineering courses. IEEE Transactions on Education, 62(4), 264-269. DOI: 10.1109/TE.2019.2899095 [GS Search]

Zichermann, G., \& Cunningham, C. (2011). Gamification by design: Implementing game mechanics in web and mobile apps (1st ed.). Sebastopol: O’Reilly Media, Inc. [GS Search]

Zorzo, A. F., Nunes, D., Matos, E., Steinmacher, I., Leite, J., Araujo, R. M., . . Martins, S. (2017). Referenciais de formação para os cursos de graduação em computação. Sociedade Brasileira de Computação (SBC). 